\title{
Biomodulina T May Restore Immunity in Older Adults
}

\author{
Gisela María Suárez-Formigo MD and Danay Saavedra-Hernández MD MS PhD
}

\begin{abstract}
Worldwide, there has been a progressive demographic shift over the past 50 years resulting in a larger proportion of older adults in the general population. Aging itself is a complex biological phenomenon characterized in part by changes in the immune system known as "immunosenescence", which makes older adults more susceptible to infectious, cardiovascular and autoimmune diseases, as well as cancers. Several strategies have been proposed in an attempt to reverse immunosenescence, including use of hormones, cytokines and thymic factors. A promising drug in the search to restore the thymic microenvironment (which plays an important role in the regulation and maintenance of the immune system) in older adults is Biomodulina T, a Cuban product registered for use in patients with recurrent respiratory infections. The administration of Biomodulina $T$ increases the number of virgin T-lymphocyte, CD4-
\end{abstract}

\section{INTRODUCTION}

Since 1950 , the proportion of the population aged $>60$ has steadily increased worldwide. WHO estimates that between 2000 and 2030 the number of people aged $>65$ will increase to approximately 973 million, representing $6.9 \%-12.0 \%$ of the world's population. By 2045, the number of seniors is projected to exceed the number of children for the first time in recorded history. An increase of $5.5 \%-11.6 \%$ is estimated in Latin America.[1] Cuba has one of the oldest populations in Latin America, with a life expectancy of 78.5 years, and $20.8 \%$ of its population aged $\geq 60$ years, a share that could reach $30 \%$ by $2030 .[2,3]$

There is a growing interest in understanding the complex biology of aging with the aim of preventing or delaying the onset of chronic age-related diseases.[4] The changes in the immune system related to age is termed immunosenescence.[5] These changes occur within an inflammatory environment, due to chronic low-grade inflammation known as "inflammaging." A state of mutual dependence is thought to occur, in which immunosenescence is induced by low-grade chronic inflammation, which in turn increases with age. Both processes help to explain the particular susceptibility of older adults to new infections and chronic diseases, including cardiovascular, neurodegenerative and metabolic diseases, as well as cancer.[5]

Several strategies have been proposed to reverse the changes that occur in the immune system with age and thus contribute to improving quality of life in older adults. Lang and colleagues defined the "3Rs" of "immune rejuvenation":

IMPORTANCE This article presents the benefits of the use of Biomodulina $\mathrm{T}$ as an immunomodulator, and its possible uses to restore immunity in older adults and immunocompromised individuals, and to improve the efficacy of immunotherapy in cancer patients. positive cells that have recently migrated from the thymus gland (recent thymic emigrants) and memory CD8-positive T-lymphocytes, which have characteristics akin to stem cells (stem cell-like memory). Furthermore, the expression of programmed cell death in CD4-Positive T-lymphocytes and CD8-Positive T-lymphocytes decreases, and the proliferative capacity of CD4-Positive T-lymphocytes increases, without changes in the frequency of regulatory T-lymphocytes. These results suggest that the administration of Biomodulina $T$ could be used to restore immunity in older adults and in other immunocompromised individuals, improve response to other immunotherapies in cancer patients, and increase the efficacy of vaccinations in older adults.

KEYWORDS Immunosenescence, aging, immunotherapy, immunomodulation, antineoplastic protocols, Cuba

replacement, by replenishing lost immune function by cells generated ex vivo; reprogramming, by regulating telomere length and stability; and restoration, to restore and maintain a normal thymic microenvironment.[6]

Recently, our group has demonstrated the capacity of Biomodulina T (BT), a polypeptide fraction derived from the bovine thymus, to expand various cellular subpopulations, contributing to a thymic-environment restorative strategy that could slow the accumulation of exhausted T cells and prevent the decrease in the number of virgin $T$ cells that occurs with aging.[7] In this article, we present suggestions based on our experiences with BT use in older patients with a history of recurrent respiratory infections without associated chronic diseases, which led to the inclusion of this drug among therapeutic options for immune system restoration.

\section{AGING AND THE IMMUNE SYSTEM}

Strategies to reverse immunosenescence This phenomenon affects practically all the components of the immune system: however, the changes most often noted in the literature are the decrease in virgin $T$ cells and increase in terminallydifferentiated memory $T$ cells, characterized by the loss of surface markers that are frequently found in virgin cells such as CD28.[8,9] The changes are attributed primarily to thymic involution,[10] chronic antigenic stimulation, nutritional impact and dysregulation of some hormonal pathways.[11,12] Immunosenescence studies in Cuba have shown that with age, virgin CD4-Positive T-lymphocytes (CD4+ T cells) decrease (unpublished author data), as do B-lymphocytes, while the number of terminally differentiated CD4+ and CD8-Positive T-lymphocytes (CD8+ T cells) increases.

The scientific literature documents application of therapeutic strategies to reverse age-associated changes in the immune system.[5] These therapeutic strategies may not only contribute to immunological restoration in older adults, but also to an enhanced immune response to the kinds of attacks that occur in infections and cancer. Regarding cancer, 
immunotherapy has opened new therapeutic possibilities in its targeted use against tumor cells.[7]

Various avenues have been suggested to counteract aging's effects on the immune system, including changes in nutrition and lifestyle, dietary supplements with specific micronutrients, modulation of $\mathrm{T}$ cell functions, as well as reduction of antigenic load and restoration of thymic function through use of steroids, hormones, growth factors and cytokines such as interleukin-7 (IL-7) and interleukin-22 (IL-22).[13] Reconstitution of the thymic microenvironment is of utmost importance for the maintenance of $\mathrm{T}$ cells with adequate repertoire diversity and intact functionality during the aging process.[14] BT is a fraction obtained from the thymus, which restores the normal thymic environment and could compensate for age-associated immune system deficits.

\section{POTENTIAL CONTRIBUTIONS OF CUBAN \\ BIOMODUUNA T}

BT is a natural immunomodulator formed by polypeptide fractions obtained from the bovine thymus. In Cuba, it is produced by the National Biopreparations Center (BIOCEN) and was registered in 1994 (Health Registration: B-08-038-J05).[15] It comes in $3 \mathrm{~mL}$ bulbs containing $3 \mathrm{mg}$ of bovine thymic fraction and is administered either intramuscularly or intravenously. Among the most frequently reported adverse reactions associated with its administration include pain and burning at the site of injection, fever, headache and fatigue.[15]

BT is useful for treating mainly cellular-type immune dysfunction manifesting as recurrent infections in older adults. This use is supported by clinical trials.[15] BT exhibits cellular regeneration and immunomodulatory properties, as it stimulates lymphoblastoid mitosis and thus normalizes the differentiation of T-lymphocytes. This activity is detectable up to at least 24 hours after administration.[15] In models of acute inflammation, edema and chronic inflammation, BT demonstrated an antiinflammatory response associated by modulation of the induced inflammatory response, and inhibited macrophage release of arachidonic acid.[15] BT's anti-inflammatory effect has been shown to operate by inhibiting release of arachidonic acid by macrophages and inflammatory cytokines, a mechanism somewhat similar to that of steroids.[16]

BT permits recovery of thymic mass in children with thymic atrophy or hypoplasia, and a subsequent increase in the release of hormones by thymic epithelial cells, possibly due to the presence of a positive feedback loop of these hormones. Additionally, a decrease in recurrent infections has been observed.[17] In a clinical trial involving patients with relapsingremitting multiple sclerosis (RRMS), clinical parameters improved and immunological parameters normalized and subsequently remained normal after BT administration, so the use of BT was suggested as a possible therapy for RRMS patients.[16] All of the above clinical studies report that BT is safe and none reported toxicity.[15,18]

\section{BIOMODUUNA T PARTIALY RESTORES CD4+} AND CD8+ T CELL COMPARTMENTS IN OLER ADULTS Expansion of virgin and memory T-lymphocytes A study recently conducted in 31 patients older than 62 with a history of recurrent respiratory infections (and absent any other previously diagnosed chronic diseases) showed that BT administration temporarily expands virgin $\mathrm{CD} 4+\mathrm{T}$ cell production, renal tubular epithelial (RTE) cell production, and stem cell-like memory CD8+ T cell production. [7] Peripheral production and maintenance of virgin T cell repertoire is critical to normal immune system function.[6] RTE cells decrease with age[19] and as a consequence of the administration of glucocortoids and cytotoxic drugs during cancer treatment. This population of memory cells with stem cell-like characteristics was only recently identified.[20] These memory $T$ cells have properties similar to those of stem cells in that they are the least differentiated population of memory cells and possess a special capacity for self-renewal.[20] Based on the evidence highlighting the replicative and self-renewing potential of these cells, their expanded presence in older populations could sustain an adequate long-term memory response capable of self-proliferation, and thus could contribute to re-establishing immune system homeostasis.

Exhaustion-resistance and potentiation of the immune system's activation and proliferation capacities In recent years, cancer immunotherapy based on treatment with immune checkpoint inhibitors such as anti Programmed Cell Death Receptor-1 (PD-1), anti Programmed Cell Death-Ligand 1 (PD-L1) and anti Cytotoxic T-Lymphocyte-associated Protein 4 (CTLA-1) has increased survival of patients diagnosed with advanced cancer in different locations.[21]

Blocking the PD-1 receptor allows T cell function to be restored in patients with advanced tumors such as melanoma and lung cancer, suggesting that depletion of the immune response is reversible in these patients.[22] BT administration decreased expression of CD4+ PD-1+ and CD8+ PD-1+ T cells, pointing to the BT thymic factor's possible anti-exhaustion value in immune response.[7]

Additionally, BT treatment increased proliferation capacity of $\mathrm{CD} 4+\mathrm{T}$ cells in older adults (as measured via expression of the Ki67 nuclear marker), as well as intracellular expression of interferon gamma, which shows that BT could constitute a potentiation strategy for increasing immune responses in older adults by contributing to restoration of the Th1 response.[7]

No expansion of regulatory $T$ cells All immune system benefits of BT described above occur in a context absent of the modification of regulatory T cells. Because BT is an extract derived from the bovine thymus, its use could be expected to stimulate thymic production of various cellular subpopulations, including natural regulatory $\mathrm{T}$ cells. However, BT administration did not change the frequency of CD4+ regulatory T cells. This result may be suggested as an additional element in favor of BT use, not only in older adults, but in cancer patients as part of a treatment regimen designed to enhance immunotherapy without the danger of increasing regulatory $T$ cells.[7]

\section{CONCLUSIONS}

BT intervention contributes to restoration of the normal thymic environment by slowing reduction of the number of virgin $T$ cells that occurs naturally during the aging process and may improve the efficacy of immunotherapy in older adults susceptible to recurrent infections and cancer. - 1 th 


\section{REFERENCES}

1. United Nations. Report of the Second World Assembly on Ageing: Madrid, 8-12 April 2002. New York: United Nations; 2002. 72 p.

2. National Health Statistics and Medical Records Division (CU). Anuario Estadistico de Salud 2019 [Internet]. Havana: Ministry of Public Health (CU); 2020 May [cited 2020 May 25]. 206 p. Available at: https://files. sld.cu/bvscuba/files/2020/05/AnuarioElectr\%c3\%b3nico-Espa\%c3\%b1ol-2019-ed -2020.pdf. Spanish.

3. Cano-Amaro M. El envejecimiento poblacional en Cuba, desde el prisma de la epidemiología social y la ética. Anales Acad Ciencias Cuba. 2016;6(2). Spanish.

4. Fulop T, Larbi A. Biology of aging: paving the way for healthy aging. Exp Gerontol. $2018 \mathrm{Jul} ; 107: 1-3$.

5. Fulop T, Larbi A, Dupuis G, Le Page A, Frost $\mathrm{EH}$, Cohen AA, et al. Immunosenescence and inflamm-aging as two sides of the same coin: friends or foes? Front Immunol. 2018 Jan;8:1960.

6. Lang PO, Govind S, Aspinall R. Reversing T cell immunosenescence: why, who, and how. Age (Dordr). 2012 Feb 25;35(3):609-20.

7. Saavedra D, Fuertes SA, Suárez GM, González A, Lorenzo-Luaces P, García B, et al. Biomodulina $T$ partially restores immunosenescent CD4 and CD8 T cell compartments in the elderly. Exp Gerontol. 2019 Jun 13;124:110633.

8. Saavedra D, García B, Lage A. T cell subpopulations in healthy elderly and lung cancer patients: insights from Cuban studies. Front Immunol. 2017 Feb 13;8:146.

9. Larbi A, Fulop T. From «truly naive» to «exhausted senescent» $T$ cells: when markers predict functionality. Cytometry Part A. 2014;85(1):2535.

10. Sauce D, Appay V. Altered thymic activity in early life: how does it affect the immune system in young adults? Curr Opin Immunol. 2011 Aug;23(4):543-8.

11. Lang PO, Samaras D. Aging adults and seasonal influenza: does the vitamin d status (h)arm the body? J Aging Res. 2012;2012:806198.
12. Lang PO, Mendes A, Socquet J, Assir N, Govind $S$, Aspinall R. Effectiveness of influenza vaccine in aging and older adults: comprehensive analysis of the evidence. Clin Interv Aging. 2012;7:55-64.

13. Fulop T, Larbi A, Hirokawa K, Mocchegiani E, Lesourds B, Castle S, et al. Immunosupportive therapies in aging. Clin Interv Aging. 2007 Mar;2(1):33-54

14. Shammas MA. Telomeres, lifestyle, cancer, and aging. Curr Opin Clin Nutr Metab Care. 2011 Jan;14(1):28-34.

15. CECMED - (Center for State Control of Medications, Equipment and Medical Devices [Internet]. Havana: CECMED; c2019. Registros. Resumen de las características del producto Biomodulina T; [cited 2020 May 25]. 3 p. Available at: https:// www.cecmed.cu/registro/rcp/biomodulinar-t -fraccion-timica. Spanish.

16. Gámez MLA, Lara RRF, Rodríguez MR, González-Quevedo MA, Fernández CR, Marzoa SN. Estudio Fase II de tratamiento de pacientes con esclerosis múltiple exacerbanteremitente con Biomodulina T. Rev Mex Neuroci. 2007;8(1):28-31. Spanish.

17. Christian López LC, Rodríguez Marín RR, Rabassa Pérez J, Santamaría Lafargue M, Romero del Sol JM, González Ross E. Efecto de la biomodulina $\mathrm{T} 1000$ sobre el timo en niños con infecciones recurrentes. Rev Cub Pediatr. 2000 Jan-Mar;72(1):3-9. Spanish.

18. García-Orihuela M, Capdevila V, Suárez-Martínez R, Rodríguez-Rivera L, Castro-González I. Efecto de la Biomodulina $T$ sobre las infecciones respiratorias altas y la polifarmacia del anciano. Rev Haban Cienc Méd. 2014 MayJun;13(3):425-36. Spanish.

19. Pido-López J, Imami N, Aspinall R. Both age and gender affect thymic output: more recent thymic migrants in females than males as they age. Clin Exp Immunol. 2001 Sep;125(3):40913.

20. Gattinoni L, Lugli E, Ji Y, Pos Z, Paulos CM, Quigley MF, et al. A human memory $T$ cell sub- set with stem cell-like properties. Nat Med. 2011 Oct;17(10):1290-7.

21. Saavedra D, Crombet T. CIMAvax-EGF: a new therapeutic vaccine for advanced non-small cell lung cancer patients. Front Immunol. 2017 Mar 13;8:269.

22. Ferrara R, Mezquita L, Auclin E, Chaput N, Besse B. Immunosenescence and immunecheckpoint inhibitors in non-small cell lung cancer patients: does age really matter? Cancer Treat Rev. 2017 Nov;60:60-8.

\section{THE AUTHORS}

Gisela María Suárez-Formigo (Corresponding author: gisela@cim.sld.cu), physician specializing in immunology. Adjunct researcher, Department of Clinical Immunology, Molecular Immunology Center (CIM), and assistant professor, Medical University of Havana, Cuba. https:// orcid.org/0000-0001-8883-4197

Danay Saavedra-Hernández, physician with dual specialties in family medicine and immunology, with a master's degree in infectious disease and a doctorate in medical sciences. Associate researcher, Department of Clinical Immunology, CIM, and assistant professor, Medical University of Havana, Cuba. https://orcid.org/0000-0002 $-6614-3819$

Submitted: February 18, 2020

Approved for publication: July 10, 2020

Disclosures: None 